\title{
Use of antipsychotics in the treatment of major depressive disorder in an outpatient mental health center
}

\author{
Carolina Garnier*, Juan Castaño, Patricia Alvaro, Rosa Sanchis, David Corcoles, Angeles Malagon, Belen Diaz, \\ Luis Miguel Martin, Antoni Bulbena
}

From $1^{\text {st }}$ International Congress on Neurobiology and Clinical Psychopharmacology and European Psychiatric Association Conference on Treatment Guidance

Thessaloniki, Greece. 19-22 November 2009

\section{Background}

Antidepressants are currently the mainstay of treatment for depression; however, almost two thirds of patients will fail to achieve remission with initial treatment. Evidence has shown that adjunctive therapy with atypical antipsychotics has the potential for beneficial antidepressant effects in the absence of psychotic symptoms [1].

\section{Materials and methods}

Using a sample of 100 patients with MDD who have been visited in Barcelona's Sant Martí Sud outpatient mental health center during the year 2008, sociodemographical (gender, age) and clinical data (toxic consume, psychiatric background, use of antipsychotics) are analysed with SPSS 15.0 statistical package

\section{Results}

Antipsychotics are used in $27 \%$ of the patients, with a predominancy in the female gender (77.8\%), a global average age of $57.9 \pm 12.6$ years. There is a predominancy of absence of psychiatric background (55.6\%) and the absence of previous hospitalisations $(66.7 \%)$. In $96.3 \%$ of the sample there was no toxic abuse.

It is observed the following distribution in the use of antipsychotics: quetiapine and olanzapine $(29.6 \%$ each one), risperidone (26\%), paliperidone (3\%). Average dose was $5.7 \mathrm{mg} / \mathrm{d}$ for olanzapine, $2.3 \mathrm{mg} / \mathrm{d}$ for risperidone, $84.5 \mathrm{mg} / \mathrm{d}$ for quetiapine and $6 \mathrm{mg} / \mathrm{d}$ for paliperidone.

\section{Conclusions}

It is observed an important frequency in the use of antipsychotic treatment for MDD, in relation with the fact that there is growing evidence for the efficacy of atypical antipsychotics for adjunctive treatment of depressive symptoms of MDD. There is scientific evidence that supports the use of the two antipsychotics predominantly used in our sample (olanzapine and quetiapine) [2], but more studies are needed to establish its place in management.

Published: 22 April 2010

\section{References}

1. Craig Nelson J, Pikalov A, Berman R: Augmentation treatment in major depressive disorder: focus on aripiprazole. Neuropsychiatr Dis Treat. 2008 4(5):937-948.

2. Shelton RC, Tollefson GD, Tohen M, Stahl S, Gannon KS, Jacobs TG, Buras WR, Bymaster FP, Zhang W, Spencer KA, Feldman PD, Meltzer HY: A novel augmentation strategy for treating resistant major depression. $A m$ J Psychiatry 2001, 158(1):131-4.

doi:10.1186/1744-859X-9-S1-S169

Cite this article as: Garnier et al:: Use of antipsychotics in the treatment of major depressive disorder in an outpatient mental health center. Annals of General Psychiatry 2010 9(Suppl 1):S169.

Department of Psychiatry, Hospital del Mar, IAPS; Barcelona, Spain 